\title{
Patient-related stressful situations and stress-related outcomes in emergency nurses: A cross-sectional study on the role of work factors and recovery during leisure time
}

\author{
A.N. de Wijn*, M.P. van der Doef \\ Institute of Psychology, Health, Medical, E Neuropsychology Unit, Leiden University, Wassenaarseweg 52, 2333 AK Leiden, The Netherlands
}

\section{A R T I C L E I N F O}

\section{Article history:}

Received 15 November 2019

Received in revised form 21 February 2020

Accepted 13 March 2020

\section{Keywords:}

[aggression]

[burnout, professional]

Critical events

Effort-recovery model

[emergency service, hospital]

Emotional demands

Job demands-resources model

[Leisure Activities]

[Nursing Staff, Hospital]

[Stress Disorders, Post-Traumatic]

\begin{abstract}
A B S T R A C T
Background: Emergency nurses are frequently exposed to patient-related stressful situations, making them susceptible to emotional exhaustion and symptoms of post-traumatic stress disorder. The current study aims to assess differential effects of patient-related stressful situations (emotionally demanding situations, aggression/conflict situations, and critical events) on stress-related outcomes in emergency nurses, and to identify moderating factors based on the Job Demands-Resources model and the Effort-Recovery model (job demands, job resources, and recovery experiences during leisure time).

Method: A cross-sectional study was carried out among nurses working in the emergency departments of 19 hospitals in the Netherlands $(N=692$, response rate $73 \%)$. Data were collected by means of an online survey. Multiple hierarchical regression analyses were performed, controlling for sociodemographic variables.

Results: The frequency of exposure to patient-related stressful situations was positively related to stressrelated outcomes, with emotionally demanding situations and aggression/conflict situations mainly explaining variance in emotional exhaustion $\left(\beta=0.16, p<.01, \Delta \mathrm{R}^{2}=0.08\right.$, and $\beta=0.22, p<.01$, $\left.\Delta \mathrm{R}^{2}=0.13\right)$, whereas critical events mainly explained variance in post-traumatic stress symptoms ( $\left.\beta=0.29, p<.01, \Delta \mathrm{R}^{2}=0.11\right)$. Moderating effects were found for within worktime recovery and recovery during leisure time. Work-time demands, autonomy and social support from the supervisor were predictive of stress-related outcomes irrespectively of exposure to patient-related stressful situations.

Conclusion: As patient-related stressful situations are difficult if not impossible to reduce in an emergency department setting, the findings suggest it would be worthwhile to stimulate within worktime recovery as well as recovery experiences during leisure time, to protect emergency nurses from emotional exhaustion and symptoms of post-traumatic stress. Furthermore, this study underscores the importance of reducing work-time demands and enhancing job resources to address stress-related outcomes in emergency nurses. Practical implications, strengths and limitations are discussed.
\end{abstract}

(c) 2020 Elsevier Ltd. All rights reserved.

\section{What is already known about the topic?}

- Emergency nurses are frequently exposed to patient-related stressful situations even more so than nurses working in other settings.

- Frequent exposure to patient-related stressful situations is related to stress-related outcomes such as emotional exhaustion and post-traumatic stress in emergency nurses.

\footnotetext{
* Corresponding author.

E-mail address: a.n.de.wijn@fsw.leidenuniv.nl (A.N. de Wijn).
}

- Research on potential moderating effects of work factors and recovery experiences during leisure time in this association is limited.

\section{What this paper adds}

- This study demonstrates that patient-related stressful situations have differential effects on stress-related outcomes in emergency nurses: Exposure to emotionally demanding situations and aggression/conflict situations has a stronger relationship with emotional exhaustion whereas exposure to critical events has a stronger relationship with post-traumatic stress symptoms. 
- Within work-time recovery and recovery experiences during leisure time can buffer the relationship between exposure to patient-related stressful situations and stress-related outcomes. Work-time demands, autonomy and social support from the supervisor are predictive of stress-related outcomes irrespectively of the exposure to patient-related stressful situations.

\section{Introduction}

Nurses working in the emergency department face a number of occupational stressors such as a high and mostly unpredictable workload, working in rotating shifts, staffing shortages, overcrowding and critical decision making under pressure (Adeb-Saeedi, 2002; Johnston et al., 2016). Moreover, due to their close contact with patients and their accompanies they are regularly confronted with patient-related stressful situations, including emotionally demanding situations, aggression and critical events (Adriaenssens et al., 2012; Copeland and Henry, 2017), even more so than nurses working in other settings (Gerberich et al., 2005; O'Connor and Jeavons, 2003).

Previous research shows that repeated exposure to patientrelated stressful situations makes nurses especially susceptible to stress-related outcomes such as emotional exhaustion and post-traumatic stress disorder (PTSD) (Adriaenssens et al., 2012; Bernaldo-De-Quiros et al., 2015; Chou et al., 2012). Not surprisingly, prevalence of stress-related outcomes in emergency nurses is high: $26 \%$ to $41 \%$ score above the cut-off for emotional exhaustion (Adriaenssens et al., 2015; Li et al., 2018) and 20-24\% report PTSD symptoms on a (sub)clinical level (Adriaenssens et al., 2012; Laposa et al., 2003). Stress-related outcomes in nurses can lead to serious consequences including depression, lower job satisfaction, increased risk of medical errors, lower productivity, more absenteeism, and higher turnover intentions (Li et al., 2018; Van Bogaert et al., 2014).

Up till now, research has mainly focused on the prevalence of patient-related stressful situations and their direct relations with stress-related outcomes in emergency nurses (Schneider and Weigl, 2018). Little research has been done investigating potential moderating factors at work and outside work that might weaken or strengthen these relationships. This research is important as patient-related stressful situations are difficult and to some extent impossible to prevent in an emergency department setting.

\subsection{Background}

The Job Demands-Resources model (Demerouti et al., 2001; Bakker and Demerouti, 2017) and the Effort-Recovery Model (Meijman and Mulder, 1998) were used as a theoretical framework for the current study. According to the Job Demands-Resources model, work factors can be categorized into job demands and job resources. Job demands are those work factors that require sustained psychological or physical effort and thereby are associated with physiological or psychological costs and eventually illness. Job resources include work factors that can facilitate the achievement of work goals, reduce the effects of job demands on health impairment and stimulate growth and development (Bakker and Demerouti, 2017). In the current study, patient-related stressful situations are identified as job demands, as these situations ask for psychological effort from the nurse (e.g. regulating one's own emotions as well as those of the patient and patients' accompanies). Following the health-impairment process of the Job Demands-Resources model, we expect that the more often emergency nurses are exposed to patient-related stressful situations, the more likely they will drain their psychological resources and experience stress-related outcomes. Furthermore, as the intensity of patient-related stressful situations differs, confrontation with these situations is expected to have differential effects on stressrelated outcomes. For example, emotionally demanding situations are low intensity situations that require emotional effort, but in general will not exceed nurses' coping resources. In contrast, critical events and aggression/conflict situations are far more likely to include high intensity stress situations and even traumatic events, defined as " ... actual or threatened death, serious injury, or sexual violence" (American Psychiatric Association, 2013, p. 271). According to Hobfoll (2001), the process of slowly running out of resources leads to "feelings of being overextended and depleted of one's emotional and physical resources" also called emotional exhaustion (Maslach et al., 2001, p. 399), whereas encountering a high intensity situation in which all coping resources are depleted at once, will rather elicit symptoms of PTSD, including uncontrolled re-experiences and avoidance of thoughts and feelings of the event (America Psychiatric Association, 2013; Gerhart et al., 2015). Indeed, a study by Adriaenssens et al. (2012) found that the frequency of reported critical events by emergency nurses was directly related to the amount of PTSD symptoms experienced. Whereas in a study by Chou et al. (2012) the frequency of negative interactions with patients (e.g. dealing with difficult or complaining patients) was directly related to emotional exhaustion in hospital nurses.

Apart from patient-related stressful situations, work-time demands are identified as demands within the framework of the Job Demands-Resources model: work-time demands require physical energy as well as psychological energy of the emergency nurse, resources that are needed when confronted with patient-related stressful situations. Thus far, research on the combined effects of various job demands on stress-related outcomes is limited (Bakker and Demerouti, 2017). A study by Jimmieson et al. (2017) among three different samples of health care professionals (hospital employees, ambulance service workers, and aged care/disability workers) found significant intensifying effects of combinations of emotional demands, cognitive demands, and work-time demands on stress-related outcomes. Furthermore, a recent study by Riedl and Thomas (2019) found that the association between emotional demands and emotional exhaustion was stronger when nurses experienced higher work-time demands. These studies suggest that exposure to multiple job demands simultaneously will lead to a faster wear out of resources, making the nurse more susceptible for stress-related outcomes.

Finally, the Job Demands-Resources model proposes that job resources can be protective and are able to buffer the effect of job demands on stress-related outcomes (Bakker and Demerouti, 2017). Within an emergency department setting, social support from colleagues and the supervisor, and autonomy have been indicated by previous research as important job resources (Adriaenssens et al., 2011; Garcia-Izquierdo and Rios-Risquez, 2012; Hunsaker et al., 2015; Johnston et al., 2016). In addition, a review by Schneider and Weigl (2018) suggested that positive social relations at work can alleviate the burden of emotional demands and work-time demands faced by emergency department staff. A promising, but far less studied resource are sources of recovery. According to the Effort-Recovery model of Meijman and Mulder (1998), recovery is necessary in order to reverse changes in the psycho-biological system due to confrontation with job demands (e.g. faster heart rate, release of hormones including cortisol), and thereby protect employees from becoming ill. In a situation where employees are regularly confronted with patientrelated stressful situations, time to process the event and restore energy levels after a highly intensive event (e.g., resuscitation), seems particularly important. Indeed, a study among ambulance personnel found that those with high scores on emotional exhaustion were also more likely to report never having time to recover between critical events (Alexander and Klein, 2001). 


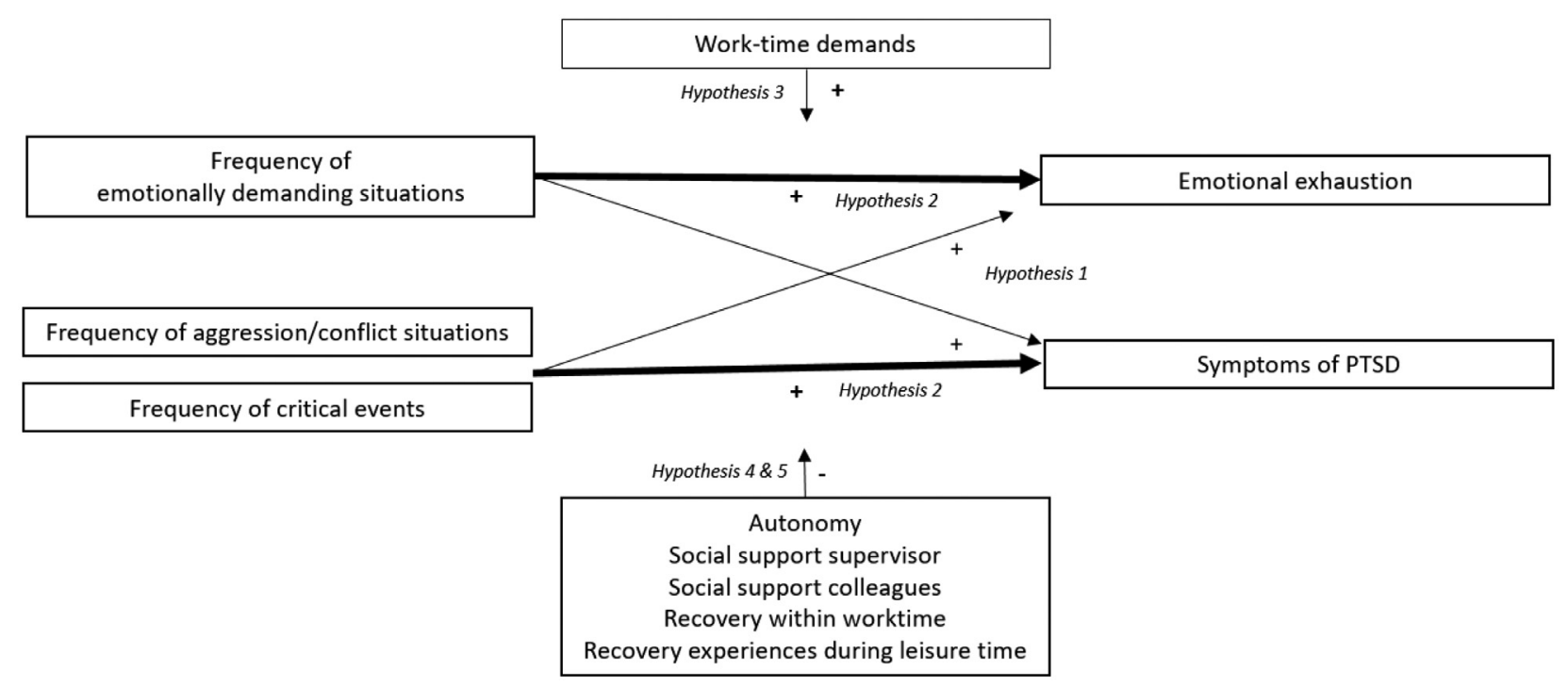

Fig. 1. Proposed hypotheses of the study.

Furthermore, recent reviews show that interventions that aim to stimulate within worktime recovery (e.g., having a break) are positively related to nurse well-being (Nejati et al., 2016; Wendsche et al., 2017). However, recovery research thus far mainly focusses on sources of recovery during leisure time (e.g. psychologically detaching from work, relaxing, degree to which persons can decide what to do during leisure time, and mastering new skills) (Sonnentag et al., 2017). These recovery experiences are related to less burnout symptoms and better well-being in studies among nurses (Poulsen et al., 2015; Singh et al., 2016). Furthermore, in other occupational groups recovery experiences appear to have a buffering role in the job demands - well-being relationship (Sonnentag et al., 2017).

The current study aims to assess buffering and intensifying work and non-work factors in the relationship between exposure to patient-related stressful situations and stress-related outcomes (emotional exhaustion and PTSD symptoms) in emergency nurses. Identifying these factors will help to direct efforts to improve the work context and recovery outside work in order to reduce and prevent stress-related outcomes in emergency nurses.

The following hypotheses are proposed (see Fig. 1):

1. Frequent exposure to patient-related stressful situations is directly and positively related to emotional exhaustion and symptoms of PTSD.

2. There is a differential effect of patient-related stressful situations on stress-related outcomes: The frequency of emotionally demanding situations is more strongly associated with emotional exhaustion than with PTSD symptoms, whereas the frequency of critical events and aggression/conflict situations is more strongly associated with PTSD symptoms than with emotional exhaustion.

3. The association between patient-related stressful situations and emotional exhaustion and PTSD symptoms is strengthened by work-time demands: Under higher work-time demands, exposure to patient-related stressful situations is more strongly related to emotional exhaustion and post-traumatic stress compared to working under lower work-time demands.

4. The association between patient-related stressful situations and emotional exhaustion and PTSD symptoms is buffered by job resources (autonomy, social support from colleagues, social support from the supervisor, and within worktime recovery).
5. On top of job resources, the relationship between patientrelated stressful situations and emotional exhaustion and PTSD symptoms is buffered by recovery experiences during leisure time (psychological detachment, mastery, control, and relaxation).

\section{Methods}

\subsection{Design}

A cross-sectional study was performed.

\subsection{Participants and setting}

The sample consisted of the 949 emergency nurses and emergency nurses in training employed in 19 hospitals in the Netherlands participating in an ongoing study on occupational stress in the emergency department.

\subsection{Data collection}

The data were collected between January 2017 and March 2017 by means of an online survey. The questionnaire took about $30 \mathrm{~min}$ to complete. Each hospital had a project leader (often the emergency department manager or a team leader) assigned to stimulate participation in the study. In addition multiple reminders were sent out resulting in a total of 692 completed questionnaires $(72.9 \%$ response). Demographic data and work-email addresses of the staff were obtained through the hospitals administration.

\subsection{Predictors}

The frequency of emotionally demanding situations and aggression/conflict situations with patients and/or accompanies were measured with an inventory of stressful situations that has been used in studies on staff working in organizations providing care for mentally and physically disabled individuals $(\alpha=0.90)$ (Bolhuis et al., 2004). The questionnaire included two subscales: the frequency of verbal and physical aggression from patients and/or accompanies (7 items) ("In my work I am confronted with patients and/or accompanies who are physically aggressive"), and the frequency of emotionally demanding situations (4 items) ("In my work I am confronted with patients in a hopeless situation"). All statements 
were rated on a 7-point Likert scale ranging from never (1) to daily (7).

In line with the study by Adriaenssens et al. (2012) critical events were measured with a single question in which emergency nurses were asked to report the number of patient-related stressful situations that they experienced as emotionally upsetting in the past six months. Responses were collected on a 7-point Likert scale ranging from none (0) to more than 5 (6).

\subsection{Outcomes}

Emotional exhaustion was measured with the Dutch version of the Maslach Burnout Inventory-Human Services Survey (Schaufeli and Van Dierendonck, 2000). The emotional exhaustion subscale included eight statements which were rated on a 7-point Likert scale from never (0) to daily (6). The Dutch version of the Maslach Burnout Inventory-Human Services Survey has shown to be a valid and reliable instrument (Schaufeli and Van Dierendonck, 2000).

Symptoms of PTSD (15 items) including avoidance ("Any reminder brought back feelings about it") and intrusion ("I thought about it when I didn't mean to") were measured with the Dutch version of the Impact of Events Scale (Horowitz et al., 1979; Van der Ploeg, Mooren, Kleber, Van der Velden, and Brom, 2004), Responses were collected on a 4-point Likert scale: not at all (0), rarely (1), sometimes (3), and often (5). The Impact of Events Scale has shown to be a reliable and valid instrument (Salsman et al., 2015).

\subsection{Moderators}

Possible moderating work factors were measured with the Leiden Quality of Work Life Questionnaire for Nurses (Gelsema et al., 2005; Maes et al., 1999): Work-time demands (5 items) (e.g. "I must care for too many patients at once"); Autonomy (4 items) (e.g. "I can decide for myself when to carry out patient-related tasks and when to carry out non-patient-related tasks"); social support from the supervisor (4 items) (e.g. "I can count on the support of my direct supervisor when I face a problem at work"); social support from colleagues (4 items) (e.g. "My colleagues give me emotional support when I'm having difficulties"). All statements were rated on a 4-point Likert scale from entirely disagree (1) to entirely agree (4). The Leiden Quality of Work Life Questionnaire for Nurses is an occupation specific questionnaire tested in multiple studies and moderate to high reliability ( $\alpha=0.67-0.96$ ) for the subscales has been found (Adriaenssens et al., 2012; Gelsema et al., 2005; Pisanti et al., 2016).

As no validated questionnaire was found in the literature to measure within worktime recovery in an emergency department setting, four items were developed to measure this construct: 1 . "If I want to, I can leave my workplace for a short while", 2. "I can have a chat during my work", 3. "During my shift, I regularly have to skip breaks", 4. "During my breaks, I must remain available for urgent cases". Responses were collected on a 4-point Likert scale from never (1) to always (4). Scores for the last two items were reversed, with higher scores indicating more within worktime recovery.

Recovery experiences during leisure time (16 items) was measured with the Dutch version of the Recovery Experiences Questionnaire (Sonnentag and Fritz, 2007; Geurts et al., 2009), including four subscales: Psychological detachment (e.g. "During the time after work I don't think about work at all”), relaxation (e.g. “during the time after work I kick back and relax"), mastery (e.g. "during the time after work I do things that challenge me"), and control (e.g. "during the time after work I feel like I can decide for myself what to do"). Each item was rated on a 5-point Likert scale ranging from never (1) to always (5).

\subsection{Ethical considerations}

Participants received an invitation for the online survey via their work-email. Informed consent was obtained at the beginning of the survey. All individual responses were anonymized by storing the data under an unique personal code. Only the authors of this paper had access to the key that links the personal code to the individual. This study was approved by the ethical review board of the university (approved on the 2nd of January 2017, CEP170102/3).

\subsection{Data analysis}

Descriptive statistics (means, standard deviations, frequencies, skewness and kurtosis) and Pearson's correlations between variables were computed. Due to non-normality of PTSD symptoms (with skewness of $1.71(S E=0.093)$ and kurtosis of 2.94 $(S E=0.186))$ a square root transformation was performed (Tabachnick \& Fidell, 1996). As this resulted in more normally distributed scores (skewness of $0.438(S E=0.093)$ and Kurtosis -0.677 $(S E=0.186))$, all analyses were done using the transformed data. Independent sample $t$-tests and $\mathrm{Chi}^{2}$ tests were performed to compare respondents and non-respondents. Next, the contribution of each predictor to each outcome and the buffering and reinforcing effects of moderators were assessed through multiple hierarchical regression analyses. Age, working experience in years, number of working hours a week, nightshifts, children between 6-21 years of age living at home and informal caregiving tasks outside work had significant correlations with the outcome variables and were therefore included as covariates in block one of the regression analysis. Gender, marital status (married/living together versus other), children under the age of 6 , supervisory role, or occupational group (registered nurse or nurse in training) had no significant correlations with the outcome variables and were therefore not included as covariates. Exposure to patient-related stressful situations was added in block two, work factors in block three, interaction terms between patient-related stressful situations and work factors in block four, recovery experiences during leisure time in block five and interaction terms between patient-related stressful situations and recovery experiences during leisure time in block six. To prevent multicollinearity, predictors (including possible moderators) were centralized around the mean (Field, 2013). Block one, two, three and five were added using forced entry of the variables. Block four and six (interaction terms) were added using the backward method to avoid suppressor effects (Field, 2013). To avoid overfitting and reduced generalizability of the findings, only significant interaction terms were included in the final model.

Visual inspection of histograms and P-P plots showed normal distributions of the standardized residuals. Scatterplots between standardized residuals and standardized predicted variables showed linear relationships and homoscedasticity. All DurbinWatson values were between one and three, and the VIF's scores below 10, indicating independent errors and a lack of multicollinearity (Field, 2013). In conclusion, all assumptions for multiple linear regression were met. A $p$-value below 0.05 was considered statistically significant.

All analyses were performed with the Statistical Package for Social Sciences (SPSS) version 23.

\subsection{Validity and reliability}

With the exception of the scales autonomy $(\alpha=0.62)$ and within worktime recovery ( $\alpha=0.59$ ), all scales had a Cronbach's Alpha above 0.70 which corresponds with an acceptable internal consistency (Tavakol and Dennick, 2011) (see Table 2). As a higher 
Table 1

Demographics respondents versus non-respondents.

\begin{tabular}{|c|c|c|c|c|c|}
\hline & & \multicolumn{2}{|c|}{ Respondents $(N=692)$} & \multicolumn{2}{|c|}{ Non-respondents $(N=257)$} \\
\hline & & M & SD & M & SD \\
\hline Age & & 42.4 & 11.3 & 43.1 & 11.9 \\
\hline Nr. of years working in the ED & & 12.1 & 11.1 & 12.9 & 11.7 \\
\hline \multirow[t]{2}{*}{ Nr. of working hours a week ${ }^{* *}$} & & 29.1 & 7.3 & 27.3 & 10.1 \\
\hline & & $N$ & $\%$ & $N$ & $\%$ \\
\hline \multirow[t]{3}{*}{ Gender } & Female & 523 & 75.6 & 186 & 72.4 \\
\hline & Male & 169 & 24.4 & 54 & 21 \\
\hline & Missing & 0 & 0 & $17^{\mathrm{a}}$ & 6.6 \\
\hline \multirow[t]{2}{*}{ Marital status } & Married/living together & 529 & 76.4 & & \\
\hline & Other & 163 & 23.6 & & \\
\hline \multirow[t]{2}{*}{ Children $<6$ years living at home } & Yes & 161 & 23.3 & & \\
\hline & No & 531 & 76.7 & & \\
\hline \multirow[t]{2}{*}{ Children 6-21 years living at home } & Yes & 217 & 31.4 & & \\
\hline & No & 475 & 68.6 & & \\
\hline \multirow[t]{2}{*}{ Informal caregiving tasks } & Yes & 157 & 22.7 & & \\
\hline & No & 535 & 77.3 & & \\
\hline \multirow[t]{2}{*}{ Occupational group } & Registered nurse & 626 & 90.5 & 225 & 87.5 \\
\hline & Nurse in training & 66 & 9.5 & 32 & 12.5 \\
\hline \multirow[t]{3}{*}{ Supervisory role* } & Yes & 31 & 4.5 & 4 & 1.6 \\
\hline & No & 661 & 95.5 & 236 & 91.8 \\
\hline & Missing & 0 & 0 & $17^{\mathrm{a}}$ & 6.6 \\
\hline \multirow[t]{2}{*}{ Night shifts } & Yes & 596 & 86.1 & & \\
\hline & No & 96 & 13.9 & & \\
\hline
\end{tabular}

internal consistency for within worktime recovery could not be achieved by deleting an item, the original four item scale was used.

\section{Results}

\subsection{Sample characteristics}

A complete overview of the sample demographics are provided in Table 1 . The majority of the respondents was female $(75.6 \%)$. The average age was 42.4 years $(S D=11.3)$, and nurses had an average of $12.1(S D=11.1)$ years of working experience in the emergency department. Compared to non-respondents, respondents worked significantly more hours a week $(M=29.1$ vs $M=27.3, p<.01)$ and had more often a supervisory role $\left(\chi^{2}=4.39, p<.05\right)$. In our sample $39.7 \%$ scored above the cut-off for high emotional exhaustion (Schaufeli and van Dierendonck, 2000), and 15.7\% reported (sub)clinical levels of PTSD symptoms (Orsillo, 2001).

\subsection{Regression analyses}

An overview of the results of the multiple regression analyses is presented in Table 3. Controlling for covariates, separate regression analyses for the three types of patient-related stressful situations (block 2) consistently showed that patient-related stressful situations were significant predictors of emotional exhaustion as well as PTSD symptoms. However, emotionally demanding situations and aggression/conflict situations explained more variance in emotional exhaustion (respectively $8 \%$ and 13\%) than in PTSD symptoms (respectively $2 \%$ and $3 \%$ ), whereas critical events explained more variance in PTSD symptoms (11\%) than in emotional exhaustion (6\%).

When adding work factors to the model (block 3 ) higher worktime demands was a strong predictor of emotional exhaustion $(\beta=0.30, p<.01, \beta=0.28, p<.01$ and $\beta=0.33, p<.01)$ and to a lesser extent of PTSD symptoms ( $\beta=0.09, p<.05, \beta=0.07$, $p>.05$, and $\beta=0.11, p<.01)$. In terms of job resources, lower autonomy was the strongest predictor of emotional exhaustion, whereas higher social support from the supervisor predicted less
PTSD symptoms as well as lower emotional exhaustion. Overall, work factors explained an additional $18-25 \%$ of the variance in emotional exhaustion and 5\% in PTSD symptoms.

When adding interaction terms (block 4) two moderating effects for the working environment were found: Recovery within worktime was a significant moderator in the relationship between emotionally demanding situations and PTSD symptoms, and social support from colleagues was a significant moderator between aggression/conflict situations and emotional exhaustion. However, the latter became insignificant when adding recovery experiences during leisure time to the model (block 5) and was therefore not interpreted. Simple slopes analysis showed under lower exposure to emotionally demanding situations, nurses with more within worktime recovery reported less PTSD symptoms compared to those with less within worktime recovery. However, when exposed to a higher number of emotionally demanding situations, nurses with higher and nurses with lower within worktime recovery experienced similar levels of PTSD symptoms (see Fig. 2).

When adding recovery experiences during leisure time to the model (block 5), direct effects for almost all recovery experiences were found, with psychological detachment having the most consistent effects. Overall, recovery experiences during leisure time explained an additional $7-8 \%$ of the variance in emotional exhaustion and $3-4 \%$ in PTSD symptoms.

On top of direct effects, a number of significant interaction effects of recovery experiences were found (block 6). Simple slope analysis showed that mastery buffered the effects of emotionally demanding situations and the effects of aggression/conflict situations on emotional exhaustion. Furthermore, when exposure to aggression/conflict situations was lower, those with more psychological detachment had lower emotional exhaustion compared to those with less psychological detachment. However, when exposed to a higher number of aggression/conflict situations this difference was not present. For PTSD symptoms, relaxation buffered the effect of aggression/conflict situations, whereas control buffered the effects of critical events. Results of these simple slopes analyses can be found in Fig. 2. 


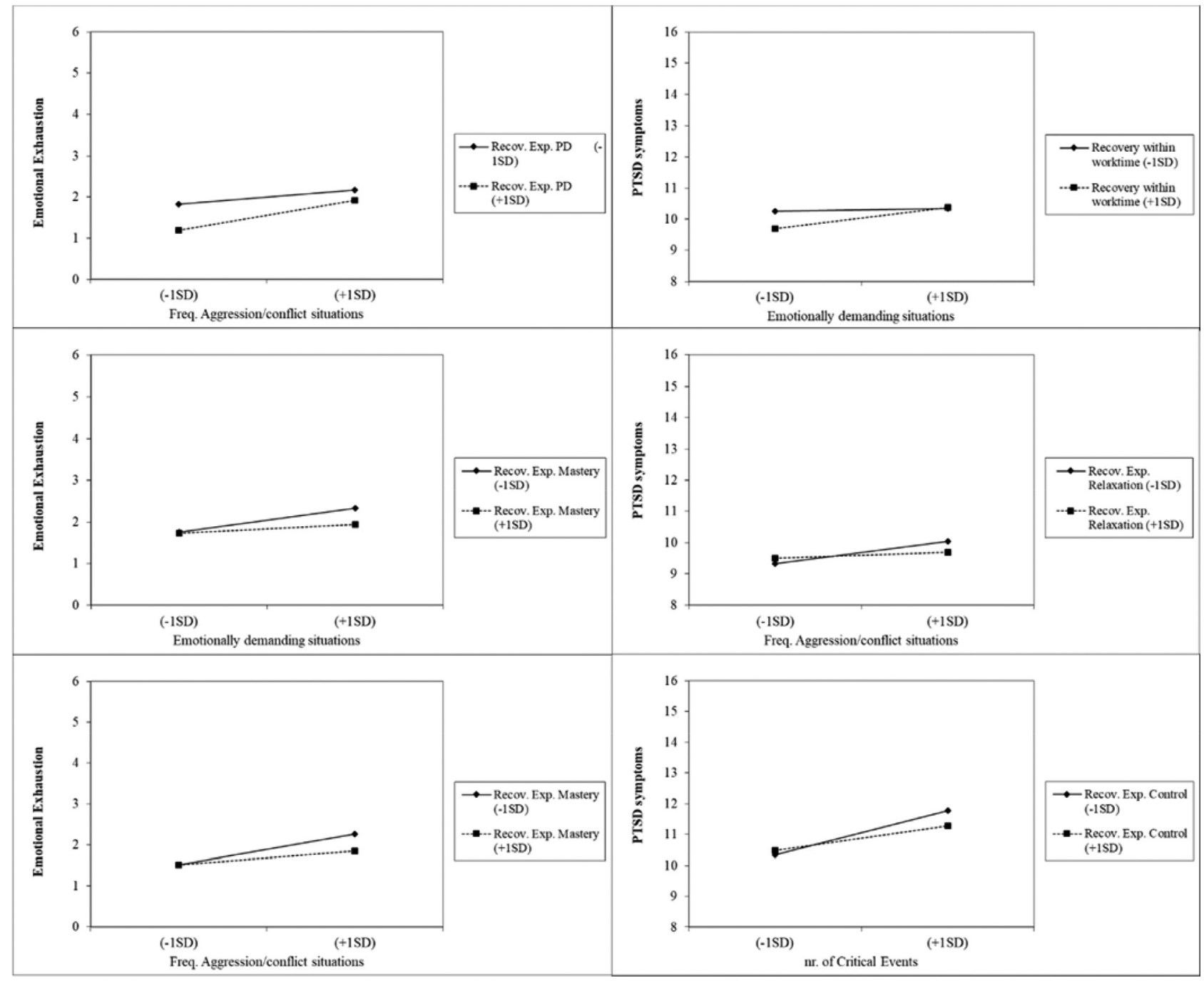

Abbreviation: Recov. Exp. = Recovery Experience, Freq. = frequency, $\mathrm{PD}=$ Psychological Detachment

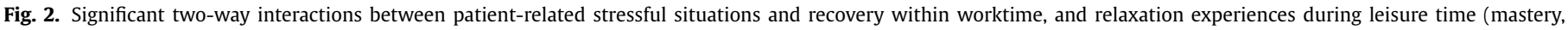
psychological detachment, relaxation) on PTSD symptoms and emotional exhaustion.

Overall, the three complete models mainly explained variance in emotional exhaustion (respectively $40 \%, 42 \%$, and $40 \%$ ), and to a lesser extent in PTSD symptoms (respectively 15\%, 15\%, and 22\%).

\section{Discussion}

In the current study the association between different types of patient-related stressful situations (emotional demanding situations, aggression/conflict situations and critical events) and stressrelated outcomes (emotional exhaustion and PTSD symptoms) in emergency nurses was examined. Furthermore, potential buffering and intensifying effects of work factors and recovery during leisure time were studied.

First of all, in line with the Job Demands-Resources model, frequent exposure to patient-related stressful situations was associated with emotional exhaustion as well as PTSD symptoms in emergency nurses. In addition, $40 \%$ of the emergency nurses in the current sample scored above the cut-off for high emotional exhaustion and 16\% reported (sub)clinical levels op PTSD symptoms. These results confirm previous studies on the high prevalence of stress-related outcomes in emergency nurses and the positive association with exposure to patient-related stressful situations
(Adriaenssens et al., 2012; Copeland and Henry, 2018; Schneider and Weigl, 2018).

Second, differential effects were found for patient-related stressful situations. As expected, emotionally demanding situations had a stronger relationship with emotional exhaustion compared to PTSD symptoms, whereas the number of critical events had a stronger relationship with PTSD symptoms than with emotional exhaustion. However, against our expectations the frequency of exposure to aggression/conflict situations was more predictive of emotional exhaustion than of PTSD symptoms. A possible explanation for this finding is that most aggressive/conflict situations that occur in the emergency department are unlikely to have a traumatic impact on emergency nurses. For example, a study by Partridge and Affleck (2017) found that from all forms of aggression, emergency nurses were most often confronted with patients using a threating tone or abusive language. In addition, a study by Bernaldo-De-Quiros et al. (2015) found that the frequency of verbal aggression was related to higher emotional exhaustion (and depersonalization), and situations including physical aggression were related to anxiety in pre-hospital emergency staff. This suggests that the less frequent and more intense forms of aggression in the emergency department are more likely to relate to anxiety related disorders, such as PTSD, whereas the more frequent and 


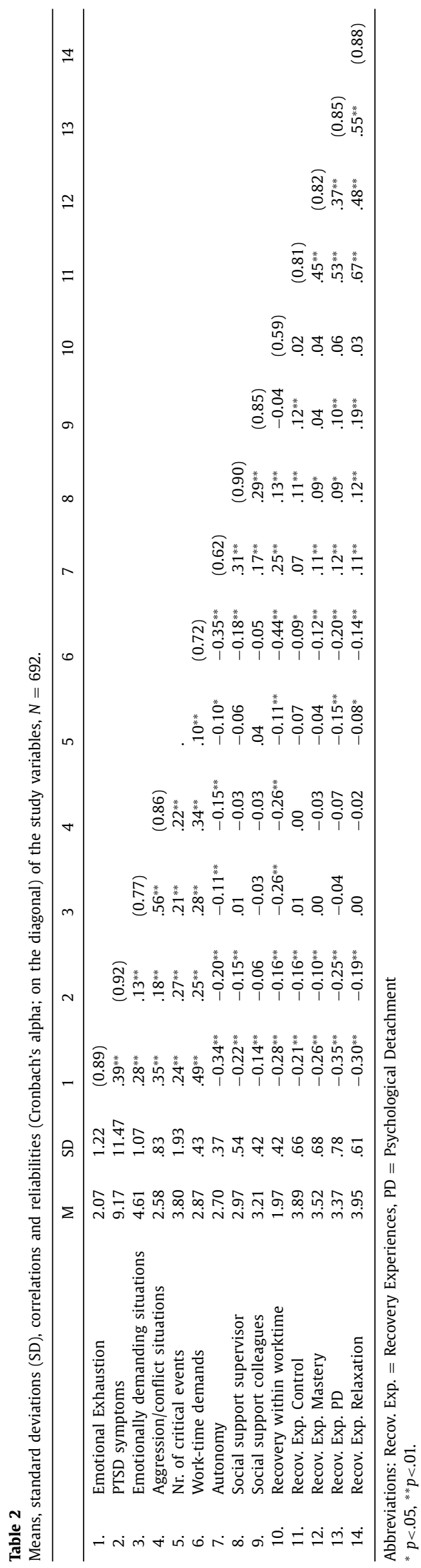

less intense forms of aggression lead to emotional exhaustion in emergency nurses.

With regard to moderating effects, against expectations nurses that experience higher work-time pressure do not experience more emotional exhaustion or PTSD symptoms when exposed to patient-related stressful situations than nurses experiencing lower work-time pressure. This is in contrast to other studies in the field that did find intensifying effects of exposure to multiple job demands on stress-related outcomes (Jimmieson et al., 2017; Riedl and Thomas, 2019). However, in the study by Jimmieson et al. (2017), whereas evidence was found for an exacerbating effect of cognitive demands (e.g. demands that ask for intense concentration) on the positive relationship between emotional demands and emotional exhaustion, this was not the case for work-time demands. Riedl and Thomas (2019) did find an intensifying effect of work-time demands on the positive relationship between emotional demands and emotional exhaustion for nurses. However, in this study work-time demands included both time-related work pressure as well as attention-related work pressure. These results suggest that the association between emotional demands and emotional exhaustion is exacerbated by cognitive demands rather than by work-time demands. Another explanation for the absence of an intensifying effect of work-time demands, is that different combinations of job demands have differential effects depending on the outcome measured. For example, although Jimmieson et al. (2017) did not find an exacerbating effect of work-time demands on the relationship between emotional demands and emotional exhaustion, work-time demands did intensify the relationship between emotional demands and sleep problems. In conclusion, more research is required to fully understand the effects of multiple job demands on the health-impairment process.

We did find some support for the buffering effect of job resources proposed by the Job Demands-Resources model: Emergency nurses reported less PTSD symptoms when they experienced high within worktime recovery rather than low within worktime recovery, but only when exposure to emotionally demanding situations was relatively low. Furthermore, no buffering effects of within worktime recovery for aggression/conflict situations or critical events were found. Neither did we find any buffering effects of autonomy, social support from the supervisor or social support from colleagues.

A possible explanation for the absence of buffering effects for most job resources might be an imperfect fit between these job resources and the demands. For example, the Demand-Induced Strain Compensation Model (DISC-Model) implies that buffering effects are more likely to be found for resources that match the demands in terms of similar processes (e.g. cognitive, behavioural, emotional) than for resources that do not match (de Jonge and Dormann, 2003) and evidence for this hypothesis has been found in several studies (Balk et al., 2019; De Jonge, Spoor, Sonnentag, Dormann, and Van den Tooren, 2012). In the current study rather broad measures of work factors were used which could have entailed an imperfect match to the demands of patient-related stressful situations. For example, emotional support might be a more fitting resource when faced with patient-related stressful situations than the more global social support measure in the current study which also includes instrumental support and appreciation.

Work factors were however important contributors to emotional exhaustion and PTSD symptoms in emergency nurses. Higher work-time demands and lower autonomy were the strongest predictors of emotional exhaustion irrespective of the exposure to patient-related stressful situations. Furthermore, social support from the supervisor was directly related to less PTSD symptoms as well as lower emotional exhaustion in emergency nurses. These findings are in line with previous research in which work-time demands, autonomy and especially social support from 
Table 3

Results of Regression of exposure to patient related stressful situations, work factors, and recovery experiences during leisure time on emotional exhaustion and PTSD symptoms ( $N=692$ ).

\begin{tabular}{|c|c|c|c|c|c|c|c|c|c|c|c|c|}
\hline & \multicolumn{2}{|c|}{ Emotional Exhaustion } & \multicolumn{2}{|c|}{ PTSD symptoms } & \multicolumn{2}{|c|}{ Emotional Exhaustion } & \multicolumn{2}{|c|}{ PTSD symptoms } & \multicolumn{2}{|c|}{ Emotional Exhaustion } & \multicolumn{2}{|c|}{ PTSD symptoms } \\
\hline & $\Delta R^{2}$ & $\beta$ & $\Delta R^{2}$ & $\beta$ & $\Delta R^{2}$ & $\beta$ & $\Delta R^{2}$ & $\beta$ & $\Delta R^{2}$ & $\beta$ & $\Delta R^{2}$ & $\beta$ \\
\hline Block 1: Covariates & $0.02^{*}$ & & $0.03^{* *}$ & & $0.02^{*}$ & & $0.03^{* *}$ & & $0.02^{*}$ & & $0.03^{* *}$ & \\
\hline Age & & 0.03 & & 0.04 & & 0.06 & & 0.06 & & 0.02 & & 0.03 \\
\hline Working experience (nr. of years) & & 0.01 & & -0.01 & & 0.00 & & -0.01 & & 0.00 & & -0.01 \\
\hline Nr. of hours working a week & & 0.02 & & -0.03 & & 0.03 & & -0.02 & & 0.03 & & -0.03 \\
\hline Nightshifts $(Y=1, N=0)$ & & -0.01 & & -0.06 & & -0.01 & & -0.07 & & -0.01 & & -0.08 \\
\hline $\begin{array}{l}\text { Children between } 6-21 \text { years living at } \\
\text { home }(Y=1, N=0)\end{array}$ & & $-0.09^{* *}$ & & -0.06 & & $-0.10^{* *}$ & & -0.06 & & $-0.11^{* *}$ & & $-0.08^{*}$ \\
\hline \multirow{2}{*}{$\begin{array}{l}\text { Informal caregiving tasks outside } \\
\text { work }(Y=1, N=0)\end{array}$} & & 0.01 & & 0.07 & & -0.01 & & 0.06 & & 0.01 & & $0.07^{*}$ \\
\hline & \multicolumn{4}{|c|}{ Block 2: Emotionally demanding situations } & \multicolumn{4}{|c|}{ Block 2: Aggression/conflict situations } & \multicolumn{4}{|c|}{ Block 2: Critical events } \\
\hline Block 2: PRSS & $0.08^{* *}$ & & $0.02^{* *}$ & & $0.13^{* *}$ & & $0.03 * *$ & & $0.06^{* *}$ & & $0.11^{* *}$ & \\
\hline PRSS & & $0.16^{* *}$ & & $0.10^{* *}$ & & $0.22^{* *}$ & & $0.12^{* *}$ & & $0.16^{* *}$ & & $0.29 * *$ \\
\hline Block 3: Work factors & $0.22^{* *}$ & & $0.05^{* *}$ & & $0.18^{* *}$ & & $0.05^{* *}$ & & $0.25^{* *}$ & & $0.05^{* *}$ & \\
\hline Work-time demands & & $0.30^{* *}$ & & $0.09 *$ & & $0.28^{* *}$ & & 0.07 & & $0.33^{* *}$ & & $0.11 * *$ \\
\hline Autonomy & & $-0.13^{* *}$ & & -0.07 & & $-0.13^{* *}$ & & -0.06 & & $-0.12^{* *}$ & & -0.05 \\
\hline Social support supervisor & & $-0.07^{* *}$ & & $-0.08^{*}$ & & $-0.08^{*}$ & & $-0.09^{*}$ & & -0.05 & & -0.07 \\
\hline Social support colleagues & & -0.04 & & 0.03 & & -0.04 & & 0.03 & & -0.06 & & 0.01 \\
\hline Recovery within worktime & & -0.06 & & -0.07 & & -0.05 & & -0.07 & & $-0.08^{*}$ & & -0.07 \\
\hline Block 4: Moderators at work & & & & $0.01 *$ & & $0.01^{* *}$ & & & & & & \\
\hline \multicolumn{13}{|l|}{ PRSS * Work-time demands } \\
\hline \multirow{2}{*}{\multicolumn{13}{|c|}{$\begin{array}{l}\text { PRSS * Autonomy } \\
\text { PRSS * Social support supervisor }\end{array}$}} \\
\hline & & & & & & & & & & & & \\
\hline PRSS * Social support colleagues & & & & & & $0.06(*)$ & & & & & & \\
\hline PRSS * Recovery within worktime & & & & $0.08^{*}$ & & & & & & & & \\
\hline Block 5: Recovery experiences & $0.08^{* *}$ & & $0.04^{* *}$ & & $0.07 * *$ & & $0.04 * *$ & & $0.07^{* *}$ & & $0.03 * *$ & \\
\hline Recov. Exp. Control & & 0.04 & & -0.06 & & 0.02 & & -0.06 & & 0.05 & & -0.04 \\
\hline Recov. Exp. Mastery & & $-0.08^{*}$ & & 0.02 & & $-0.09^{*}$ & & 0.02 & & $-0.10^{* *}$ & & 0.01 \\
\hline \multirow{2}{*}{$\begin{array}{l}\text { Recov. Exp. PD } \\
\text { Recov. Exp. Relaxation }\end{array}$} & & $-0.18^{* *}$ & & $-0.17^{* *}$ & & $-0.18^{* *}$ & & $-0.17^{* *}$ & & $-0.16^{* *}$ & & $-0.14^{* *}$ \\
\hline & & $-0.12^{* *}$ & & -0.03 & & $-0.10^{*}$ & & -0.02 & & $-0.11^{*}$ & & -0.02 \\
\hline Blok 6: Moderators outside work & $0.01^{* *}$ & & & & $0.01^{*}$ & & $0.01^{*}$ & & & & $0.01^{*}$ & \\
\hline PRSS * Recov. Exp. Control & & & & & & & & & & & & $-0.09^{*}$ \\
\hline PRSS * Recov. Exp. Mastery & & $-0.08^{* *}$ & & & & $-0.08 *$ & & & & & & \\
\hline PRSS * Recov. Exp. PD & & & & & & $0.09^{* *}$ & & & & & & \\
\hline PRSS * Recov. Exp. Relaxation & & & & & & & & $-0.07^{*}$ & & & & \\
\hline$R^{2}$ model & 0.40 & & 0.15 & & 0.42 & & 0.15 & & 0.40 & & 0.22 & \\
\hline Adj. $R^{2}$ model & 0.39 & & 0.13 & & 0.40 & & 0.13 & & 0.38 & & 0.20 & \\
\hline
\end{tabular}

Abbreviations: $Y=$ yes, $N=$ No, Recov. Exp. $=$ Recovery Experiences during leisure time, $\mathrm{PD}=$ Psychological Detachment, PRSS $=$ Patient-related stressful situations, $\beta=$ Beta at last sign. block, $\Delta R^{2}=$ change in explained variance, sign. $=$ significant, Adj. $=$ Adjusted. ${ }^{*} p<.05,{ }^{* *} p<.01 .\left({ }^{*}\right)$ significant at $p<.01$ before adding block 5 . 
the supervisor has been found to be directly related to emergency nurses well-being (Adriaenssens et al., 2012; Basu et al., 2017; Schneider and Weigl, 2018).

Finally, we assessed whether apart from the influence of work factors, recovery experiences during leisure time could buffer the negative effects of patient-related stressful situations. First of all, we found direct effects of recovery experiences on the well-being of emergency nurses, with the strongest effects for psychological detachment. This finding - including the importance of psychological detachment in comparison to the other recovery experiences - is in line with previous studies (Sonnentag et al., 2017). Second, confirming the Effort-Recovery model (Meijman and Mulder, 1998), recovery experiences buffered the association between patientrelated stressful situations and stress-related outcomes. This implies that, similar to what has been found in other occupations (Sonnentag et al., 2017), engaging in recovery experiences during leisure time is important for emergency nurses to regain their resources and protect them for stress-related outcomes.

\subsection{Strengths, limitations and future directions}

The large number of participants $(N=692)$ in the study working in different hospitals all over the Netherlands, the high response rate (73\%), and the use of an occupation specific questionnaire to measure work factors are important strengths of this study. Furthermore, this study is innovative as it is the first to examine the differential effects of patient-related stressful situations on stress-related outcomes, and the impact of recovery within worktime and recovery experiences outside work as buffers in the relationship between patient-related stressful situations and stressrelated outcomes in emergency nurses.

However, some limitations must be taken into account when interpreting the results. First of all, the cross-sectional design of the study does not permit any conclusions regarding the causal relationship between the variables. Although it seems more likely that patient-related stressful situations cause stress-related health complaints, we cannot rule out that emergency nurses experiencing emotional exhaustion or PTSD symptoms perceive patient-related stressful situations as occurring more frequently or interpret situations more often as emotionally upsetting. Similarly, we cannot rule out that those nurses that experience stress-related outcomes might also have difficulty to engage in recovery experiences. Up till now only a small number of longitudinal studies have been done on recovery experiences during leisure time and their results regarding causality remain inconclusive (Sonnentag et al., 2017).

In addition to the cross-sectional design, data was based solely on self-report measures which might have led to common method bias (Podsakoff, Mackenzie, and Lee, 2003). However, a study by Siemsen et al. (2010) shows that considering multivariate linear relationships, adding independent variables with common method variance to the model generally leads to a reduction rather than an increase of common method bias (Siemsen et al., 2010). Furthermore, they argued that interaction effects cannot be artifacts of, but can be deflated by common method variance (Siemsen et al., 2010), providing further support for the interaction effects found in the current study. Still, especially considering work factors, future studies may benefit from adding more objective measures (e.g. number of patients visiting the emergency department).

A final limitation to this study includes the moderate internal consistency of the scale measuring within worktime recovery. One possible reason for this is that the current scale measures different types (e.g. short unofficial breaks and official breaks) and experiences (e.g. opportunities for detachment from work by leaving the workplace for a short while) of recovery during worktime, which could have led to a lower internal consistency.
Taking these limitations into account, in future research longitudinal designs are necessary to gain more insight in the causal relationships between patient-related stressful situations, work factors, recovery experiences during leisure time and stress-related outcomes in emergency nurses. Furthermore, we suggest to extend the scale measuring within worktime recovery and differentiate between official breaks, micro breaks and recovery experiences during breaks, based on recent recovery research (Bosch and Sonnentag, 2019; Kim et al., 2018). In terms of directions, based on previous research regarding the Demand-Induced Strain Compensation Model (de Jonge and Dormann, 2003), it would be worthwhile to study the buffering effects of more focused resources matching the specific patient-related demands.

\subsection{Practical implications}

Providing that longitudinal studies confirm the findings of the current study, the following recommendations are warranted.

First of all, although patient-related stressful situations are to some extent inherent to the emergency department setting, effort should be invested to reduce the number of these situations. Relevant measures in this respect could be, for example, providing information on the processes in the emergency department and current waiting times (See and Catterson, 2017), providing adequate pain management (Husebo et al., 2014), and education and training for emergency nurses on ways to prevent/manage aggressive behavior (Kynoch et al., 2011). Second, due to their direct relationship with stress-related outcomes, it is important to lower worktime demands and ensure adequate levels of job resources. Special attention might be given to guarantee recovery within worktime and stimulate recovery during leisure time. Current reviews show that interventions can stimulate within worktime recovery which in turn increases well-being of nurses (Nejati et al., 2016; Wendsche et al., 2017). Furthermore, training including education on recovery experiences, reflecting on one's current recovery experiences, and goal setting to achieve more recovery experiences, has been found effective on both achieving more recovery experiences as well as better well-being (Hahn et al., 2011). Finally, as performing work-related activities during leisure time is related to less recovery experiences (Sonnentag et al., 2017), hospital management may stimulate psychological detachment from work by ensuring that employees are not required to read work-related emails, attend work-related courses, or take calls for work-related problems during their leisure time.

\section{Conclusion}

Exposure to patient-related stressful situations is an inevitable part of the job of emergency nurses and is related to emotional exhaustion and symptoms of PTSD. In the current study within worktime recovery and recovery during leisure time were found to be important resources, whilst other work factors were directly associated with these stress-related outcomes. The results emphasize the importance of ensuring adequate job resources, reducing work-time demands, and stimulating recovery during leisure time, to safeguard emergency nurses' well-being.

\section{CRediT authorship contribution statement}

A.N. de Wijn: Conceptualization, Data curation, Formal analysis, Writing - original draft. M.P. van der Doef: Conceptualization, Data curation, Formal analysis, Funding acquisition, Writing - original draft. 


\section{Funding}

This research was financially supported by Stichting IZZ. The funding sources had no role in the study design, the collection, analysis and interpretation of the data, in the writing of the report, and in the decision to submit the article for publication.

\section{Conflict of Interest}

No conflict of interest has been declared by the authors.

\section{Acknowledgements}

We would like to thank all the participants for their contribution in this study.

\section{References}

Adeb-Saeedi, J., 2002. Stress amongst emergency nurses. Aust. Emerg. Nurs. J. 5 (2), 19-24. doi:10.1016/s1328-2743(02)80015-3.

Adriaenssens, J., de Gucht, V., Maes, S., 2012. The impact of traumatic events on emergency room nurses: findings from a questionnaire survey. Int. J. Nurs. Stud. 49 (11), 1411-1422. doi:10.1016/j.ijnurstu.2012.07.003.

Adriaenssens, J., De Gucht, V., Maes, S., 2015. Determinants and prevalence of burnout in emergency nurses: a systematic review of 25 years of research. Int. J. Nurs. Stud. 52 (2), 649-661. doi:10.1016/j.ijnurstu.2014.11.004.

Adriaenssens, J., De Gucht, V., Van Der Doef, M., Maes, S., 2011. Exploring the burden of emergency care: predictors of stress-health outcomes in emergency nurses. J. Adv. Nurs. 67 (6), 1317-1328. doi:10.1111/j.1365-2648.2010.05599.x.

Alexander, D.A., Klein, S., 2001. Ambulance personnel and critical incidents: impact of accident and emergency work on mental health and emotional well-being. Br. J. Psychiatry 178 (1), 76-81.

American Psychiatric Association, 2013. Diagnostic and Statistical Manual of Mental Disorders: Diagnostic and Statistical Manual of Mental Disorders, 5th Edition American Psychiatric Association, Arlington, VA.

Bakker, A.B., Demerouti, E., 2017. Job demands-resources theory: taking stock and looking forward. J. Occup. Health Psychol. 22 (3), 273-285. doi:10.1037| ocp0000056.

Balk, Y.A., De Jonge, J., Oerlemans, W.G.M., Geurts, S.A.E., 2019. "What a match!": the specific role of resources in the relation between demands and vigour in elite sport. Appl. Psychol. 69 (1), 120-147 doi:10.1111/apps.12188.

Basu, S., Qayyum, H., Mason, S., 2017. Occupational stress in the ED: a systematic literature review. Emerg. Med. J. 34 (7), 441-447. doi:10.1136/ emermed-2016-205827.

Bernaldo-De-Quiros, M., Piccini, A.T., Gomez, M.M., Cerdeira, J.C., 2015. Psychological consequences of aggression in pre-hospital emergency care: cross sectional survey. Int. J. Nurs. Stud. 52 (1), 260-270. doi:10.1016/j.ijnurstu.2014.05.011.

Bolhuis, P., Mandos, E., \& Hollander, M. (2004). Kwaliteit van Arbeid in de Gehandicaptenzorg: Medewerkersraadpleging 2004

Bosch, C. Sonnentag, S, 2019. Should i take a break? a daily reconstruction study on predicting micro-breaks at work. Int. J. Stress Manag. 26 (4), 378-388 $10.1037 /$ str0000117.

Chou, H.Y., Hecker, R., Martin, A., 2012. Predicting nurses' well-being from job demands and resources: a cross-sectional study of emotional labour. J. Nurs. Manag. 20 (4), 502-511. doi:10.1111/j.1365-2834.2011.01305.X.

Copeland, D., Henry, M., 2017. Workplace violence and perceptions of safety among emergency department staff members: experiences, expectations, tolerance, reporting, and recommendations. J. Trauma Nurs. 24 (2), 65-77. doi:10.1097/JTN. 0000000000000269.

Copeland, D., Henry, M., 2018. The relationship between workplace violence, perceptions of safety, and professional quality of life among emergency department staff members in a level 1 trauma centre. Int. Emerg. Nurs. 39, 26-32. doi:10.1016/j.ienj.2018.01.006.

de Jonge, J., Dormann, C., 2003. The disc model: demand-induced strain compensation mechanisms in job stress. In: Dollard, M.F., Winefield, H.R., Winefield, A.H. (Eds.), Occupational Stress in the Service Professions. Taylor \& Francis, London, pp. 43-74.

Demerouti, E., Bakker, A.B., Nachreiner, F., Schaufeli, W.B., 2001. The job demandsresources model of burnout. J. Appl. Psychol. 86 (3), 499-512. doi:10.1037/ 0021-9010.86.3.499.

De Jonge, J., Spoor, E., Sonnentag, S., Dormann, C., Van den Tooren, M., 2012. "Take a break?!" off-job recovery, job demands, and job resources as predictors of health, active learning, and creativity. Eur. J. Work Organ. Psychol. 21, 321-348. doi:10.1080/1359432X.2011.576009.

Field, A., 2013. Discovering Statistics using SPSS, 4th ed. Sage, London.

Garcia-Izquierdo, M., Rios-Risquez, M.I., 2012. The relationship between psychosocial job stress and burnout in emergency departments: an exploratory study. Nurs. Outlook 60 (5), 322-329. doi:10.1016/j.outlook.2012.02.002.

Gelsema, T.I., van der Doef, M., Maes, S., Akerboom, S., Verhoeven, C., 2005. Job stress in the nursing profession: the influence of organizational and environmental conditions and job characteristics. Int. J. Stress Manag. 12 (3), 222-240. doi:10.1037/1072-5245.12.3.22210.1037/1072-5245.12.3.222.
Gerberich, S.G., Church, T.R., McGovern, P.M., Hansen, H., Nachreiner, N.M., Geisser, M.S., Jurek, A., 2005. Risk factors for work-related assaults on nurses. Epidemiology 16 (5), 704-709, doi:10.1097/01.ede.0000164556.14509.a3.

Geurts, S., De Bloom, J., Kompier, M., \& Sonnentag, S. (2009). De herstelervaringen vragenlijst: Nederlandse vertaling van de recovery experiences questionnaire. Ongepubliceerd manuscript. Radboud Universiteit Nijmegen. Behavioural Science Instituut. Sectie arbeids- en organisatiepsychologie. Nijmegen.

Gerhart, J., Canetti, D., Hobfoll, S., 2015. Traumatic stress in overview: definition, context, scope, and long-term outcomes. In: Cherry, K. (Ed.), Traumatic Stress and Long-Term Recovery. Springer, New York, NY, pp. $3-24$.

Hahn, V.C., Binnewies, C., Sonnentag, S., Mojza, E.J., 2011. Learning how to recover from job stress: effects of a recovery training program on recovery, recoveryrelated self-efficacy, and well-being. J. Occup. Health Psychol. 16 (2), 202-216. doi:10.1037/a0022169.

Hobfoll, S.E., 2001. The influence of culture, community, and the nested-self in the stress process: advancing conservation of resources theory. Appl. Psychol. 50 (3), 337-421. doi:10.1111/1464-0597.00062.

Horowitz, M., Wilner, N., Alvarez, W., 1979. Impact of event scale: a measure of subjective stress. Psychosom. Med. 41 (3), 209-218.

Hunsaker, S., Chen, H.C., Maughan, D., Heaston, S., 2015. Factors that influence the development of compassion fatigue, burnout, and compassion satisfaction in emergency department nurses. J. Nurs. Scholarship 47 (2), 186-194. doi:10.1111 jnu.12122.

Husebo, B.S., Ballard, C., Cohen-Mansfield, J., Seifert, R., Aarsland, D., 2014. The response of agitated behavior to pain management in persons with dementia. American Journal of Geriatric Psychiatry 22 (7), 708-717. doi:10.1016/j.jagp. 2012.12.006.

Jimmieson, N.L., Tucker, M.K., Walsh, A.J., 2017. Interaction effects among multiple job demands: an examination of healthcare workers across different contexts Anxiety Stress Coping 30 (3), 317-332. doi:10.1080/10615806.2016.1229471.

Johnston, A., Abraham, L., Greenslade, J., Thom, O., Carlstrom, E., Wallis, M., Crilly, J., 2016. Review article: staff perception of the emergency department working environment: integrative review of the literature. Emerg. Med. Aust. 28 (1), 7-26. doi:10.1111/1742-6723.12522.

Kim, S., Park, Y., Headrick, L., 2018. Daily micro-breaks and job performance: general work engagement as a cross-level moderator. J. Appl. Psychol. 103 (7), 772-786 doi:10.1037/apl0000308.

Kynoch, K., Wu, C.J., Chang, A.M., 2011. Interventions for preventing and managing aggressive patients admitted to an acute hospital setting: a systematic review. Worldviews Evid. Based Nurs. 8 (2), 76-86. doi:10.1111/j.1741-6787.2010.00206. $\mathrm{x}$.

Laposa, J.M., Alden, L.E., Fullerton, L.M., 2003. Work stress and posttraumatic stress disorder in ED nurses/personnel. J. Emerg. Nurs. 29 (1), 23-28. doi:10.1067/men. 2003.7.

Li, H., Cheng, B., Zhu, X.P., 2018. Quantification of burnout in emergency nurses: a systematic review and meta-analysis. Int. Emerg. Nurs. 39, 46-54. doi:10.1016/j. ienj.2017.12.005.

Maes, S., Akerboom, S., van der Doef, M., Verhoeven, C., 1999. De Leidse Arbeids Kwaliteits Schaal voor Verpleegkundigen (LAKS-V). In: The Leiden Quality of Work Life Questionnaire for Nurses (LQWLQ-nurses). Health Psychology, Leiden University, Leiden.

Maslach, C., Schaufeli, W.B., Leiter, M.P., 2001. Job burnout. Annu. Rev. Psychol. 52, 397-422. doi:10.1146/annurev.psych.52.1.397.

Meijman, T.F., Mulder, G., 1998. Psychological aspects of workload. In: Drenth, P.J.D., Thierry., H. (Eds.), Handbook of Work and Organizational Psychology. Psychology Press, Hove, pp. 5-33.

Nejati, A., Shepley, M., Rodiek, S., 2016. A review of design and policy interventions to promote nurses' restorative breaks in health care workplaces. Workplace Health Saf. 64 (2), 70-77. doi:10.1177/2165079915612097, quiz 78.

O'Connor, J., Jeavons, S., 2003. Nurses' perceptions of critical incidents. J. Adv. Nurs. 41 (1), 53-62. doi:10.1046/j.1365-2648.2003.02506.x.

Orsillo, S.M., 2001. Measures for acute stress disorder and posttraumatic stress disorder. In: Antony, M.M., Orsillo, S.M. (Eds.), Practitioner's Guide to Empirically Based Measures of Anxiety. Kluwer Academic/ Plenum, New York, pp. 255-307.

Partridge, B., Affleck, J., 2017. Verbal abuse and physical assault in the emergency department: rates of violence, perceptions of safety, and attitudes towards security. Aust. Emerg. Nurs. J. 20 (3), 139-145. doi:10.1016/j.aenj.2017.05.001.

Pisanti, R., van der Doef, M., Maes, S., Meier, L.L., Lazzari, D., Violani, C., 2016. How changes in psychosocial job characteristics impact burnout in nurses: a longitudinal analysis. Front. Psychol. 7, 1082. doi:10.3389/fpsyg.2016.01082.

Poulsen, M.G., Poulsen, A.A., Khan, A., Poulsen, E.E., Khan, S.R., 2015. Recovery experience and burnout in cancer workers in Queensland. Eur. J. Oncol. Nurs. 19 (1) 23-28. doi:10.1016/j.ejon.2014.08.003.

Posakoff, P.M., Mackenzie, S.B., Lee, J., Podsakoff, N.P., 2003. Method biases in behavioral research: a critical review of the literature and recommended remedies. J. Appl. Psychol. 88 (5), 879-903. doi:10.1037/0021-9010.88.5.879.

Riedl, E.M., Thomas, J., 2019. The moderating role of work pressure on the relationships between emotional demands and tension, exhaustion, and work engagement: an experience sampling study among nurses. Eur. J. Work Organ. Psychol. 28 (3), 414-429. doi:10.1080/1359432x.2019.1588251.

Salsman, J.M., Schalet, B.D., Andrykowski, M.A., Cella, D., 2015. The impact of events scale: a comparison of frequency versus severity approaches to measuring cancer-specific distress. Psychooncology 24 (12), 1738-1745. doi:10.1002/pon. 3784. 
Siemsen, E., Roth, A., Oliveira, P., 2010. Common method bias in regression models with linear, quadratic, and interaction effects. Organ. Res. Methods 13 (3), 456476. doi:10.1177/1094428109351241.

Schaufeli, W.B., Van Dierendonck, D., 2000. Utrechtse Burnout Schaal (UBOS). Handleiding [Utrecht Burnout Scale. Manual]. Swets \& Zeitlinger, Lisse. The Netherlands.

Schneider, A., Weigl, M., 2018. Associations between psychosocial work factors and provider mental well-being in emergency departments: a systematic review. PLoS ONE 13 (6), e0197375. doi:10.1371/journal.pone.0197375.

See, J.A., Catterson, P., 2017. Can improving information to patients about emergency department processes reduce aggressive behaviour towards staff? Emerg. Med. Aust. 29 (5), 597-598. doi:10.1111/1742-6723.12858.

Singh, P., Burke, R.J., Boekhorst, J., 2016. Recovery after work experiences, employee well-being and intent to quit. Person. Rev. 45 (2), 232-254. doi:10.1108/ pr-07-2014-0154.

Sonnentag, S., Fritz, C., 2007. The recovery experience questionnaire: development and validation of a measure for assessing recuperation and unwinding from work. J. Occup. Health Psychol. 12 (3), 204-221. doi:10.1037/1076-8998.12.3.204.
Sonnentag, S., Venz, L., Casper, A., 2017. Advances in recovery research: what have we learned? What should be done next? J. Occup. Health Psychol. 22 (3), 365380. doi:10.1037/ocp0000079.

Tavakol, M., Dennick, R., 2011. Making sense of Cronbach's alpha. Int. J. Med. Educ. 2, 53-55. doi:10.5116/ijme.4dfb.8dfd.

Van Bogaert, P., Timmermans, O., Weeks, S.M., van Heusden, D., Wouters, K. Franck, E., 2014. Nursing unit teams matter: impact of unit-level nurse practice environment, nurse work characteristics, and burnout on nurse reported job outcomes, and quality of care, and patient adverse events-a cross-sectional survey. Int. J. Nurs. Stud. 51 (8), 1123-1134. doi:10.1016/j.ijnurstu.2013.12.009.

Van der Ploeg, E., Mooren, T.T.M., Kleber, R.J., van der Velden, P.G., Brom, D., 2004 Construct validation of the Dutch version of the impact of event scale. Psychol. Assess. 16 (1), 16-26. doi:10.1037/1040-3590.16.1.16.

Wendsche, J., Ghadiri, A., Bengsch, A., Wegge, J., 2017. Antecedents and outcomes of nurses' rest break organization: a scoping review. Int. J. Nurs. Stud. 75, 65-80. doi:10.1016/j.ijnurstu.2017.07.005. 